\title{
Vermicomposting: An Effective Alternative for Organic Solid Waste Management
}

\author{
A. Grewal, S. S. Hundal, S. Sharma \\ Punjab Agricultural University \\ Ludhiana 141004, India \\ ann.grwl@gmail.com; sshundal@pau.edu; sandyagro@ rediffmail.com
}

\section{Extended Abstract}

Increased human settlements and industrialisation have led to agglomeration of organic solid wastes. The disposal and efficient management of these wastes is vital for creating healthy environment and encourage resource recycling. Vermicomposting is a simple biotechnological process of composting, in which certain species of earthworms are used to enhance the process of waste conversion and produce a valuable end product. Vermicomposting process shows great potential in the degradation of organic solid wastes, wherein wastes are converted into effective biofertilzers rich in nutrients.Vermicomposting process is faster than composting and varies significantly from the latter. The present study was designed to test the vermicomposting potential of Eisenia fetida in rice based residues: rice husk (RH), paddy straw (PS) and spent mushroom paddy straw (SMPS). The wastes were amended with farmyard manure in the ratio $1: 1$ and samples were drawn every 15 day beginning 30 days after the set up of the experiment to a maximum of 90 days. The nutritional status of different compost and vermicompost samples was analysed. A comparison was made between the vermicompost and compost obtained at the end of the experiment. The earthworms showed high affinity towards all the substrates under consideration, resulting in the complete conversion of substrate into vermicompost in shorter time duration, which accentuates the fact that vermicomposting process is faster than composting. The duration of vermicompost was in the order RH:FYM >PS:FYM >SMPS:FYM. According to the investigation, the fastest conversion of substrate into compost was found in spent mushroom paddy straw substrate, which took 75 days for the formation of final vermicompost. The laboratory analysis for nutrient composition revealed an appreciable change in the nutrient content of the vermicompost and the compost but the nutritional content of the vermicompost was found to be higher than the compost obtained from the same substrate. The samples showed a gradual surge in the NPK (\%) levels and a decrease in the $\mathrm{pH}$ and total organic carbon content $(\%)$. The best vermicompost as a soil fertilizer was SMPS which showed the highest increment and final content of $\mathrm{N}(72 \%), \mathrm{P}(37 \%)$ and $\mathrm{K}(50 \%)$ by the end of the experiment. Therefore the study proves vermicomposting to be a better alternative for sustainable management of organic solid wastes to create a healthy environment.

Keywords: Organic solid wastes, Composting, Eisenia fetida, Vermicomposting, Waste management 